\title{
El control y explotación de la mano de obra colona en la hacienda andina peruana*
}

\section{Jorge Gascón Gutiérrez}

Grupo de Investigaciones Andinas Universidad de Barcelona

El presente artículo quiere ser una aportación al conocimiento de los mecanismos de control ejercidos por la hacienda andina sobre sus trabajadores. La tesis principal es que estos mecanismos eran, primordial aunque no exclusivamente, económicos: se fundamentaban en la necesidad de la población colona de acatar unas relaciones de producción que, a la vez que la explotaban, le permitían subsistir y reproducirse. Para explicar esta ambivalencia se utiliza un concepto creado y desarrollado por Carlos Marx: el de "coerción sorda de las relaciones económicas". Se usan como fuente entrevistas realizadas a colonos de las haciendas de la isla de Amantaní, en el lago Titicaca.

"Qué corazón podríamos tener para quejarnos al patrón, decían, cómo vamos a quejarnos del patrón, el dueño de la tierra, el dueño de la hacienda. Nosotros estamos viviendo en la propiedad del patrón, nos beneficiamos con el agua, con el pasto,... Así hablaban todos en favor del patrón"

Hugo NEIRA

Huillca: habla un campesino peruano

Afirma Anrup ${ }^{1}$ que las formas de control y las estructuras de dominación de la hacienda andina han sido insuficientemente estudiadas. Podríamos añadir que cuando esto ha sucedido, normalmente ha sido en el seno de investigaciones más amplias, cuyo interés no era exclusivamente la hacienda o las relaciones sociales de producción que en ellas se establecían.

El presente trabajo quiere ser una aportación a este campo. En concreto, pretendemos discernir cuáles eran los mecanismos económicos en los

* He de agradecer a los profesores Pilar García Jordán de la Universidad de Barcelona, Rodrigo Montoya de la UNMSM (Lima), Pedro Quintín de la Universidad del Valle (Cali), y Andrés Guerrero de FLACSO (Quito), así como a los miembros del Grupo de Investigaciones Andinas de la Universidad de Barcelona (profesores Jesús Contreras, Oriol Beltrán y Andreu Viola, Ester Pérez Berenguer e Imma Querol) sus comentarios a las ideas que aquí se exponen. Y muy especialmente a los amantaneños Alfredo V. Cari y Juan Mamani, por su amistad y apoyo durante el trabajo de campo.

1 Anrup, Roland: El taita y el toro: En torno a la configuración patriarcal del régimen hacendado cuzqueño. Gotemburgo/Estocolmo, 1990. 
que se sostenía el sistema de hacienda, y que permitían a los propietarios nominales de la tierra mantener en un estado de subordinación a los campesinos que la trabajaban y enajenarles su excedente de trabajo y producción.

\section{Un estado de la cuestión}

La mayor parte de las explicaciones sobre las estructuras de dominación de la hacienda andina se han centrado en las formas de coerción extraeconómicas. Incluso para algunos autores, la enajenación de los excedentes campesinos sólo era posible mediante mecanismos como la violencia. ${ }^{2}$ Otros encuentran las causas de la subordinación de la población colona en aspectos ideológicos, tales como la acción de los clérigos, que predicaban la resignación y la obediencia, o la función de la fiesta en su faceta catártica, que liberaba al campesino oprimido de sus tendencias agresivas al romper las estructuras establecidas durante un breve espacio de tiempo sin poner en peligro el orden social. ${ }^{3}$

Sin embargo, en el presente artículo pretendemos incidir en un aspecto que la bibliografía sobre el tema ha tratado parcial o superficialmente, cuando no ha obviado: los mecanismos de carácter económico que permitían a los propietarios mantener una relación social de producción de tipo servil con sus trabajadores, y que consideramos los esenciales.

Posiblemente el endeudamiento o servidumbre por deudas ha sido el sistema de coerción económica más investigado. ${ }^{4}$ Estos estudios han evi-

2 Para Manrique, Jorge: "Lanas, circuitos mercantiles, violencia, estructuras de poder, resistencia, en el sur peruano", en García Jordán / Izard (comp.): Conquista y resistencia en la historia de América. Barcelona, 1992, págs. 289-299, mientras que en las sociedades capitalistas la ganancia comercial aparece como resultado del simple juego de las fuerzas del mercado, en las sociedades precapitalistas subyugadas a una economía de mercado la ganancia comercial sólo se logra si el vendedor entrega su mercancía por debajo de su valor, lo que exige el uso de la coerción extraeconómica.

Manrique está en la misma línea que Laclau, Ernesto: "Imperialism in Latin America", New Left Review, 67, 1971, y Cardoso, Ciro F.S. y Pérez Brignoli, Héctor: Historia económica de América Latina: Sistemas agrarios e historia colonial. Barcelona, 1987, quienes, al referirse al área latinoamericana en general, afirman que la forma servil de explotación se basa en la coacción extraeconómica que permite al grupo dominante acaparar los excedentes campesinos.

3 El trabajo de Anrup: El taita y... es un buen ejemplo de investigación de este tipo, al hacer una enumeración exhaustiva de estos factores. Al referirse al gamonalismo, Manuel Burga y Alberto Flores Galindo (Apogeo y crisis de la República Aristocrática. Lima, 1987) también hablan de la utilización de ciertos elementos mágico-religiosos extraídos de la cultura popular, con los que se revestían los miembros del grupo dominante serrano ante los ojos campesinos.

4 Más adelante profundizaremos en este tema. 
denciado que el endeudamiento tenía una doble faceta: por un lado, impedía al colono eximirse de las relaciones sociales de producción en las que estaba inmerso; por otro, aseguraba al campesino su acceso a la tierra y a una parte de los excedentes de la hacienda.

El principal problema con el que se enfrentan estos estudios, a la hora de entender el funcionamiento del sistema de dominación servil, es su carácter parcial, pues el endeudamiento es sólo una forma de coerción entre otras que permiten la reproducción de las relaciones de producción existentes en la hacienda. Por lo tanto, no puede explicar por sí solo la complejidad de los mecanismos de dominación. Esta falta de globalidad puede crear la sensación de que, al obtener ambos agentes sociales beneficios de la servidumbre por deudas, propietario y trabajador vivían en un equilibrio entre pares, olvidando que para el hacendado se trataba de un mecanismo de dominación y control de la mano de obra, y para el campesino de supervivencia. ${ }^{5}$

Alberti y White, ${ }^{6}$ y en cierta medida también Cotler, ${ }^{7}$ desarrollaron en los años 70 una tesis sobre el funcionamiento de las relaciones de dominación, que aspira a dar una explicación del fenómeno en su totalidad. ${ }^{8}$ Para ellos, el poder del hacendado se fundamentaba en el control de los recursos materiales (capital, tierras,...) e inmateriales (prestigio, información,...). El propietario utilizaba este poder para, en primer lugar, aislar al colono de un mundo exterior (mercado, instituciones gubernamentales, etc.) que quedaba mediatizado a través de su figura, y en segundo lugar, para establecer relaciones individuales con los campesinos y limitar las relaciones entre ellos.

Manrique $^{9}$ ha criticado este modelo negando que las relaciones económicas intercampesinas fuesen muy limitadas o inexistentes. Ciertamente, se daban relaciones de producción entre los colonos que tomaban formas de reciprocidad (ayni, minka,...), y ello iba acompañado de institu-

5 Brass, Tom: "Unfree Labour and Capitalist Restructuring in the Agrarian Sector: Peru and India”, The Journal of Peasants Studies, vol. 14, n. ${ }^{\circ} 1.1986$, págs. 50-77; hace una interesante crítica a este posicionamiento donde el colono parece salir beneficiado con el sistema de endeudamiento.

6 Alberti, Giorgio: "Los movimientos campesinos", en La hacienda, la comunidad y el campesino en el Perú. Lima, 1970; Whiyte, William Foote y Alberti, Giorgio: Power, Politics and Progress: Social change in Rural Peru. New York/Amsterdam,1976.

7 Cotler, Julio: "Haciendas y comunidades tradicionales en un contexto de movilización política”, en Matos Mar (comp.): Hacienda, comunidad y campesinado en el Perú. Lima, 1976, págs. 311-342.

8 Esta tesis fue recogida posteriormente por Caballero, José María: Economía agraria de la sierra peruana en los albores de la reforma agraria. Lima, 1980.

9 Manrique, Nelson: Yawar Mayu: Sociedades terratenientes serranas: 1879-1910. Lima, 1988. 
ciones políticas e ideológicas, semejantes a las de comunidades libres, que permitían la reproducción de estas relaciones (cargos comunales, fiestas, etc.). Aunque esta crítica es acertada, pensamos que el principio teórico en el que se fundamenta el modelo (el control de los recursos por parte del hacendado) es correcto. Y que también lo es que este control permitía el aislamiento del campesino de hacienda del mundo exterior. Pero este aislamiento no se daba tanto por la acción de mecanismos extraeconómicos (prohibición de salir de la hacienda, obligación de casarse entre colonos,...), que también existían o podían existir, como por otros estrictamente materiales: la enajenación del sobretrabajo y de la sobreproducción del que era objeto el colono le impedía tener relaciones con el mercado laboral y de bienes, pues carecía de mercancías con las que interrelacionar. A lo largo del artículo desarrollaremos esta tesis. En esta misma línea, Deere ${ }^{10}$ ha descubierto como las haciendas de la Sierra Norte del Perú controlaron la mano de obra campesina hasta bien entrado el siglo XX gracias a que monopolizaban la tierra; es decir, a que controlaban los medios de producción.

Las relaciones de producción existentes en la hacienda también han sido tratadas en numerosos estudios cuyo objetivo era discernir cuáles fueron las causas del fracaso de la modernización (en el cambio tecnológico y en las relaciones de producción) del fundo surandino. Este tema ha generado un intenso debate. Una de las tesis que más éxito ha tenido es la del "asedio interno" planteada por Martínez Alier ${ }^{11}$ según el cual numerosos hacendados promovieron un proceso de modernización, pero fracasaron ante la oposición de sus colonos; la propiedad nominal de la tierra no suponía, por tanto, su pleno control. ${ }^{12}$

10 Deere, Carmen Diana: Familia y relaciones de clase: El campesinado y los terratenientes en la sierra norte, 1900-1980. Lima, 1992.

11 Martínez Alier, Juan: Los huacchilleros del Perú: Dos estudios de formaciones sociales agrarias. Francia, 1973. La tesis del asedio interno ha sido aceptada y desarrollada, entre otros, por: Bertram, Geoffrey: "New Thinking on the Peruvian Highland Peasantry", Pacific Viewpoint, 15, 1974, págs. 89-110; Flores Galindo, Alberto: Arequipa y el Sur Andino: Siglos XVII-XX. Lima, 1977; Thorp, Rosemary y Bertram, Geoffrey: Perú: 1890-1977: Crecimiento y políticas en una economía abierta. Lima, 1988; Stein, William W.: El caso de los becerros hambrientos y otros ensayos de antropología económica peruana. Lima, 1991; Jacobsen, Nils: Mirages of Transition: The Peruvian Altiplano, 1780-1930. Berkcley and Los Angeles/London,1993; Quintín Quílez, Pedro: Hacendados, comuneros y comerciantes en el Ocongate del siglo XX: Transformaciones en las estructuras de mediación política y de articulación económica en la Sierra Sur del Perú. Tesis doctoral, Univ. de Barcelona, 1994; y Anrup, R. y Ramírez, R.: "Aparcería y disposición en una hacienda cafetera de Tolima (La Aurora, 1948-1993)”, Anuario de Estudios Americanos, LIII: 1. Sevilla, 1996, págs. 175-193.

12 Esta idea ya había sido planteada por Bourricaud, François: Cambios en Puno. México, 1967. 


\section{El área de estudio: la isla de Amantaní}

Para desarrollar nuestro trabajo nos centraremos en un espacio territorial delimitado: Amantaní, la isla más grande y poblada que Perú tiene en el Lago Titicaca, y que durante más de cuatro siglos fue tierra de haciendas.

Las relaciones sociales de producción establecidas entre propietarios y colonos eran de tipo servil. Estas relaciones se caracterizaban por permitir al colono el usufructo de parte de la tierra de la hacienda, a cambio de sufrir la enajenación de su sobretrabajo y su sobreproducción. En condiciones normales, es decir, siempre que las relaciones entre colono y hacendado se mantenían en los cauces prescritos, las parcelas que usufructuaba el campesino pasaban de generación en generación. Por tradición, el contrato entre propietario y campesino también establecía que las nuevas familias que se formasen se quedasen en la hacienda a la que pertenecían sus padres; éstos cedían parte de sus propios terrenos a la nueva pareja, la cual posteriormente realizaba un nuevo contrato con el hacendado.

El trabajo del colono para el fundo era esencialmente agrícola, pero también estaba obligado a realizar labores para los propietarios como personal doméstico. Aunque estos servicios fueron abolidos oficialmente a principios del siglo XX, en Amantaní no perdieron vigencia hasta poco antes de la venta de las haciendas a los campesinos a mediados de siglo.

\section{La coerción sorda de las relaciones económicas}

La principal tesis del presente artículo es que los mecanismos de dominación en los que se sostenía el sistema de haciendas eran básica, aunque no exclusivamente, infraestructurales. ${ }^{13}$ En concreto, entendemos que el factor fundamental que permitía el control y la explotación de la población colona era la necesidad de esta población de acatar unas relaciones de producción que la explotaban pero que, a la vez, le permitían subsistir y reproducirse; es lo que Marx llama "la coerción sorda de las relaciones económicas". ${ }^{14}$

13 Nos situamos en la misma línea que Archetti, Eduardo P.: "Relaciones de producción en el campo: el problema del feudalismo y de la coacción extraeconómica", en Campesinado y estructuras agrarias en América Latina. Quito, 1981, págs.173-196, quien afirma que las relaciones de producción "feudales" existentes en la hacienda latinoamericana se explican por razones económicas. Para este autor, el factor principal era el acceso a la tierra, pues el control de la mano de obra colona se realizaba monopolizando los recursos productivos. Nuestro artículo pretende ser un desarrollo de esta tesis.

14 Marx, Carlos: El Capital: Crítica de la Economía Política. Madrid, 1973. 
Esta coerción sorda, en el caso que nos ocupa, operaba básicamente a dos niveles. El primero hace referencia a la forma de tenencia de la tierra. El campesino usufructuaba unas parcelas cedidas por la hacienda. Esto le obligaba a aceptar las relaciones de producción serviles en las que estaba inmerso, pues en caso contrario el propietario nominal de la tierra le habría privado de esas parcelas que eran su medio de subsistencia. El segundo nivel se encontraba en la relación del campesino con los mercados capitalistas de bienes y de trabajo. Distintos mecanismos enajenaban al colono su excedente de producción y de trabajo; de esta manera, el acceso a los mercados capitalistas de bienes y de trabajo le era vetado, pues carecía de mercancía con la que interactuar. Así, se impedía que realizase una primera acumulación de capital que le podría haber permitido romper su dependencia de los medios de producción cedidos por el propietario.

\section{El primer nivel de la coerción sorda: el acceso a la tierra}

Las siguientes transcripciones, extraídas de un juicio entablado muy tardíamente por un hacendado amantaneño contra sus colonos, evidencian como funcionaba este primer nivel de la coerción sorda de las relaciones económicas. ${ }^{15}$ El propietario Emiliano Arias, dueño de la hacienda Arias y, por matrimonio, de la Herrera, entró en conflicto con sus colonos, posiblemente por el deseo de acrecentar o sostener la extracción de los excedentes campesinos en un momento (finales de la década de 1940) en que el sistema de hacienda ya estaba en crisis. Así explican los colonos acusados en el juicio la presión a que se vieron sometidos por parte del hacendado:

\footnotetext{
"Por otra parte don Emiliano Arias (...) quiere a todo evento apropiarse de nuestras tierras, manifestando que dentro de los linderos de sus títulos están nuestras propiedades i que el presentante i muchas decenas de familias que tenemos nuestras casas o nuestros terrenos donde hemos vivido desde tiempos inmemoriales le pertenecen a él i que todos debemos desocupar o sino servirles de colonos i pagar por las tierras que ocupamos, concepto inventado por don Emiliano Arias que ha hecho consentir a las autoridades políticas, donde hemos tenido que esclarecer i desvirtuar las pretensiones que abriga el señor Arias con respecto a nuestras tierras."
}

15 Archivo Departamental de Puno. Instrucción seguida a denuncia de Emiliano Arias Sosa contra Romualdo Ccari, José Pacompía Elequén y Anastasio Pacompía por robo y daños materiales. 17 de julio de 1949. 
En demanda de sus reclamaciones, y en este contexto de tensión con Arias, los colonos de las dos haciendas llegaron a realizar una huelga de brazos caídos. Pero finalmente esta protesta fracasó ante la amenaza de expulsión, ya que los colonos "no tienen donde ir".

"OTROSI. - Hago presente que el robo se ha producido cuando los indígenas colonos de las Hdas. Arias y Herrera estuvieron en una huelga de brazos caídos y nos encontrábamos en comparendos y trámites administrativos para ver si volvían al trabajo o abandonaban las Hdas. que es lo que ha debido ocurrir, pero que habiéndose sometido muchos de los indígenas a seguir trabajando porque no tienen a donde ir, es que se ha normalizado en parte la situación de trabajo en la Isla."

En resumen, la dependencia de los medios de producción obligó a los colonos a acatar las relaciones de producción, ya que era mediante estas relaciones como podían acceder a esos medios.

Como hemos visto en el primer fragmento transcrito, aunque el amantaneño no poseía la propiedad de iure de las parcelas que usufructuaba, de facto se consideraba su dueño:

"Todas [las tierras] eran del misti. Por su servicio daba tierras. Luego los colonos decían 'es mi tierra'. Pero a la gente daba el misti. No había tierra propia de la gente. La daba el misti y la gente decía 'es mi tierra'." (Juan Juli, gr. 5bis.91).

Y así era, siempre y cuando se sometiese a las relaciones sociales de producción en las que se hallaba inmerso. En estas condiciones, es lógico que el campesino colono se identificase con la hacienda y que temiese una posible expulsión, pues su acceso a la tierra estaba mediatizado por el contrato que le ataba al fundo. En este sentido, el campesino era plenamente consciente de la prerrogativa del propietario a desahuciarle:

"Si un colono no hacía caso al misti, el misti le echaba de la hacienda." (Manuel Quispe, entr. 6-90).

"El trato de los mistis era muy malo. El campesino que no hacía caso era expulsado de sus tierras y le quitaban sus chacras." (Manuel Mamani, entr. 8-90).

La memoria colectiva, en forma de narraciones, le recordaba su posición inestable y de dependencia al hacendado. Dos casos de desahucio, que a varias décadas de la desaparición de las haciendas aún perduran en el recuerdo colectivo, ejemplifican el temor del amantaneño a perder el acceso a la tierra. El primero explica las peripecias de un grupo de colonos despachados de sus respectivas haciendas y, por ende, de Amantaní, pues rara- 
mente un colono expulsado era aceptado por otra hacienda de la Isla. Seis fueron los colonos expulsados: Celestino Quispe y su hijo Domingo, Simón Pacompía, un tal Fortunato, y los apodados Purisaca y Malatito. Al menos los dos primeros pertenecían a la hacienda Luna, y Purisaca a la de Natalia Herrera. La razón del desahucio fue que se trataba de "rateros" reincidentes. Una vez en tierra firme se encontraron con Máximo Arias, propietario de una de las haciendas de Amantaní, quien se los llevó "por compasión" a trabajar a Marcapata, en la ceja de selva cusqueña. Posiblemente Máximo Arias también poseía tierras o administraba alguna hacienda en esa zona. Al poco tiempo se dirigieron a Cusco, donde de nuevo fueron contratados para ir a trabajar a la selva, esta vez a Quillabamba. Ahí residieron durante varios años, hasta que finalmente regresaron a Puno para morir, aquejados de enfermedades tropicales. Nunca se les permitió retornar a Amantaní.

Los acontecimientos de la segunda narración debieron acaecer en la década de 1920. El padre de Simón Calsín fue acusado de robar productos del almacén de la hacienda Arias, a la que pertenecía. Este fue el punto de partida de una serie de conflictos entre propietario y colono que desembocó en la expulsión de este último y su familia. En este caso parece ser que el desahucio venía favorecido por el hecho de que los Calsín no eran colonos antiguos de la hacienda, sino que pertenecían, en origen, a la hacienda Ávila; la familia había heredado el puesto de colono en el fundo Arias a través del padrino de bautizo del abuelo de Simón Calsín, Manuel Suaña, que no tenía hijos. Atemorizados por la perspectiva de expulsión, la familia Calsín consultó su problema con el paqo Lino, de la parcialidad de Sancayuni, quien les aconsejó realizar un pago a la tierra. Poco después recibieron un comunicado de Arias para que toda la familia se presentase ante él en Puno, "de rodillas". Los Calsín pensaban que ya nunca más podrían regresar a la Isla. Cuando llegaron a Puno, la mujer del hacendado tuvo una conversación con la esposa de Calsín, a la que reprendió duramente por haber permitido que su marido realizase las acciones de las que se le acusaba y frecuentase determinadas malas compañías. Finalmente las demandas de perdón y clemencia de la familia Calsín fueron aceptadas. La familia Calsín, de ser una de las más conflictivas, se convirtió en la más fiel a Arias, como demuestra que posteriormente el padre de Simón Calsín fuera nombrado mayordomo y se hiciera cargo de las llaves de la casa-hacienda y del almacén, y que con el tiempo el propio Simón heredara este cargo. Los Calsín, unas pocas décadas después, se caracterizarían por su decidida 
defensa del hacendado frente a las luchas campesinas que se generaron por el deseo de los colonos de adquirir las tierras que trabajaban.

Pero el desahucio no era una medida recurrente y fácil de adoptar por los propietarios. Por el contrario, eran raras las ocasiones en las que tenía lugar, y sólo, como hemos visto en estas narraciones, cuando el colono repetía con insistencia el motivo de la expulsión:

"El misti no podía botar a los colonos. Sólo cuando habían problemas. Cuando los colonos hacían problemas cuatro o cinco veces. Cuando hacían una o dos veces no botaba." (Simón Calsín, gr. 1.92/93).

Y es que, como sucedía frecuentemente en la hacienda serrana, la propiedad del fundo no suponía su pleno dominio. El ausentismo, que alejaba al dueño de sus posesiones y le dificultaba actuar sobre ellas de forma directa, o en palabras de Bourricaud, "el complejo sistema de tradiciones"16 al que estaba ligado, son motivos a tener en cuenta. Pero la principal razón hay que achacarla al temor a la reacción campesina. Si el acceso a la tierra era el factor coercionador sordo que impelía al campesino a acatar una relación de producción servil, la expulsión de la hacienda sin un motivo razonable a sus ojos, es decir, la precariedad del acceso a los medios de producción, podía llevarle a poner en duda y a contestar aquellas relaciones sociales. En otras palabras, si el factor coercionador sordo no está garantizado tampoco lo está su infalibilidad. Las decisiones que pudiese tomar el propietario de la tierra no respondían simplemente a sus intereses, sino que también dependían de los límites establecidos por las relaciones sociales de producción en las que participaba.

Se podría alegar que al colono siempre le quedaba la posibilidad de abandonar la hacienda y vender su fuerza de trabajo como trabajador libre. No obstante, hemos de considerar el contexto económico de la región surandina peruana de la segunda mitad del siglo XIX y de la primera del XX, donde no existía un mercado libre de trabajo. La región estaba volcada en la producción de lana para la exportación y de bienes agroalimentarios para el autoconsumo y el mercado interno. Ambas actividades se producían en las comunidades y en las haciendas; es decir, en el seno de relaciones sociales de producción no-capitalistas. La escasa población asalariada eran funcionarios del Estado, empleados de las casas exportadoras arequipeñas, administradores de haciendas, etc., pero no se había desarrollado aún un

16 Bourricaud: Cambios en..., pág. 85. 
mercado de trabajadores productivos libres (obreros rurales o industriales), que es el único tipo de trabajo al que el campesino serrano podría haber aspirado. Es cierto que muchas haciendas contrataban a campesinos de las comunidades aledañas para realizar tareas en los momentos del ciclo agropecuario en que más mano de obra se requería, pero estos trabajos eran temporales y sólo permitían a los comuneros equilibrar su economía doméstica, pero no liberarse de sus medios de producción.

\section{El segundo nivel de la coerción sorda: la relación con los mercados capitalistas de bienes y de trabajo}

El campesino-colono surandino formaba parte de la base productiva del mercado capitalista internacional que le extraía sus excedentes en forma de productos y/o trabajo. Pero esto no significa que se relacionase con este mercado de forma capitalista. ${ }^{17}$ Por el contrario, el amantaneño se hallaba imbricado en unas relaciones sociales de producción no-capitalistas; no había un pago de salarios al trabajador, ni un mercado libre de trabajo, ni una separación del trabajador de los medios de producción, características todas ellas de una relación de producción capitalista ${ }^{18}$ sino que se hallaba imbricado en unas relaciones sociales de producción serviles que le coartaban el acceso directo al mercado capitalista.

Su relación con ese mercado, por tanto, quedaba mediatizada por la figura del hacendado. Esta mediación se encarnaba en diversos mecanismos por los que el hacendado enajenaba el excedente campesino. De esta manera, el colono veía reducidas drásticamente sus posibilidades de interactuar con el mercado capitalista de bienes, al carecer de productos para mercar; e igualmente, como también era enajenado de su sobretrabajo, no podía venderse temporalmente como mano de obra en el mercado capitalista de trabajo. ${ }^{19}$

17 El desarrollo del sistema capitalista no supone necesariamente la desaparición de las relaciones de producción no-capitalistas, sino su subsunción. Montoya, Rodrigo: A propósito del carácter predominantemente capitalista de la economía peruana actual (1960-1970). Lima, 1978; Peña, Sergio de la: Capitalismo en cuatro comunidades campesinas. México, 1986; Godelier, Maurice: "L'anàlisi dels procesos de transició", Antropologies, 1, 1987, págs. 25-31.

18 Montoya, Rodrigo: Capitalismo y no capitalismo en el Perú: Un estudio histórico de su articulación en un eje regional. Lima, 1980; Meillassoux, Claude: Mujeres, graneros y capitales. México, 1987.

19 A esto hay que sumar otras medidas extraeconómicas, más explícitas, tomadas por los hacendados: prohibiciones de salir de la isla sin permiso, exoneración del servicio militar, etc. 
En síntesis, al sistema le era imprescindible desligar al campesino de sus excedentes, ya no sólo para obtener beneficios económicos, sino también para mantener su estado de dependencia. De lo contrario, el colono habría tenido la posibilidad de acumular un capital e independizarse de los medios de producción cedidos por el propietario; es decir, de romper con el primer nivel de la coerción sorda de las relaciones económicas y emanciparse. El principal mecanismo de exoneración de los excedentes del campesino de hacienda era el establecido por el contrato de colonaje, que por sí solo ya suponía la enajenación de la mayor parte de su sobretrabajo. Pero no era el único.

\section{El hacendado como comerciante}

Aun con todo, el aislamiento del colono respecto al mercado capitalista de bienes no era absoluto. Las ocasiones que el amantaneño tenía de relacionarse directamente con este mercado eran escasas, en parte debido a que las pocas veces que tenía oportunidad de salir de la Isla era para trabajar para el hacendado, transportando la producción o para realizar labores domésticas en las casas de los propietarios, que vivían en Puno u otras ciudades más alejadas; pero especialmente porque, al serle enajenados sus excedentes, su nivel de monetarización era muy bajo.

Con el dinero que conseguía vendiendo parte de su producción, compraba sal, pimienta y coca, si bien en los últimos años en que se mantuvo en vigencia el sistema de hacienda el número de productos adquiridos de esta manera aumentó considerablemente: azúcar, arroz, pan, petróleo, cerillas, alcohol, pinturas, sombreros, algodón, productos manufacturados, objetos ceremoniales, ornamentos para fiestas, etc. ${ }^{20}$

"Los colonos no vendían cosecha. Normalmente sobraba, pero había que guardar. Pero siempre llevábamos a Puno una arrobita, algo así, para vender. No harto." (Carmelo Calsín, gr. 2.94).

Sin embargo, aunque no estaba generalizado, algunos hacendados procuraban que estas relaciones comerciales también se realizasen a través de ellos, asumiendo el papel de comerciantes. Con ello reducían todavía

20 Avalos de Matos, Rosalía: "Changements culturels dans les iles du lac Titicaca", Travaux de l'Institut Francais d'Etudes Andines, 3, 1951, págs. 40-50. 
más los ya escasos contactos de los colonos con el mercado. Y de paso acaparaban parte del excedente campesino en forma de ganancia comercial.

\section{El endeudamiento}

El tema del endeudamiento del colono ha generado una cierta controversia respecto a quien sale beneficiado con este sistema. Frente a la tesis clásica, que afirma que el endeudamiento servía a los intereses hacendados (permitía extraer la sobreproducción y el sobretrabajo de los trabajadores, y retenerles en la hacienda), en los últimos años han surgido otras opuestas. ${ }^{21}$ Para los autores que apoyan estas nuevas tesis, el colono también saca provecho del sistema de endeudamiento. Algunos sostienen que el endeudamiento le aseguraba su trabajo y no ser expulsado de la hacienda: ${ }^{22}$ el colono deseaba seguir en la hacienda y mantener el mismo tipo de relaciones serviles, pues sus ingresos como tal eran superiores a los que podía percibir como obrero rural y su nivel de vida era superior al de los pequeños parcelarios. ${ }^{23}$

Otros afirman que, si bien el endeudamiento ataba la mano de obra (ya fuese porque el colono no podía marchar de la hacienda sin cubrir su deuda, o porque los préstamos permitían estabilizar la economía de la familia colona y así mantener su complacencia para quedarse en el fundo) y aseguraba su reemplazo generacional (las deudas se transmitían por herencia), el colono también salía favorecido en cuanto que era una deuda perenne que nunca se llegaba a cubrir. En este caso, al colono le interesaba endeudarse, ya que una mayor deuda no acarreaba un mayor desgaste laboral, y por el contrario, mayor era el acceso a los excedentes de la hacienda y más alto su nivel de vida. ${ }^{24}$

Posiblemente habría que comprender el endeudamiento como una institución que a lo largo de la historia, a medida que el contexto socio-económico fue variando, tuvo efectos distintos. En origen fue creada por el grupo dominante en favor de sus intereses: en un contexto de fuerte demanda

21 Paralelamente, se ha generado una controversia sobre el sistema de enganche de trabajadores libres por parte de la hacienda andina. Para una visión general de esta polémica, véase Bedoya Garland, Eduardo: "Bonded Labor, coercion and capitalist development in Perú", Quaderns de l'ICA, 10, 1997, págs. 9-38.

22 Blanchard, P: "The Recruiment of Workers in the Peruvian Sierra at the Turn of the Century: The Enganche System”, Interamerican Economic Affairs, 33: 3, 1979, págs. 62-85; Figueroa, Adolfo: Capitalist Development and the Peasant Economy in Peru. Cambridge, 1984.

23 Martínez Alier: Los huacchilleros del....

24 Guerrero, Andrés: La semántica de la dominación: El concertaje de indios. Quito, 1991; Jacobsen: Mirages of transition... 
de mano de obra fue usada por el hacendado para liberar al campesino comunero o minifundista de sus medios de producción y convertirlo en colono, ${ }^{25}$ y una vez alcanzado este fin, para retenerlo en la hacienda. Pero con el tiempo, este contexto varió; la mano de obra, hasta entonces un bien escaso, se volvió excedentaria, ya fuese por el crecimiento demográfico, intenso desde el siglo XVIII, o por el interés que mostraron algunos hacendados surandinos en las primeras décadas del siglo XX en desarrollar los medios productivos, lo que pasaba por reducir el número de colonos. ${ }^{26}$ Ahora el hacendado no podía desligarse de su excedente de trabajadores debido a las obligaciones contraídas con ellos. En parte, estas obligaciones venían generadas por el sistema de endeudamiento, que de ser una institución que le beneficiaba pasó a convertirse en un lastre. El hacendado quedó atrapado, de nuevo, en aquel "complejo sistema de tradiciones" del que hablaba Bourricaud, o como dice Deere, "limitado por las relaciones de clase de las que formaba parte". ${ }^{27}$

En el caso amantaneño, el endeudamiento se daba con cierta asiduidad, y era vital para la subsistencia y reproducción del grupo doméstico campesino. La agricultura es una actividad arriesgada en términos económicos a causa de su dependencia de los fenómenos meteorológicos. En las zonas aledañas al Titicaca el riesgo se multiplica, por ser estos fenómenos muy comunes. Aunque en un año con cosecha aceptable ésta era suficiente para mantener al grupo doméstico, una helada, una sequía o una granizada podían desequilibrar la economía familiar. En estos casos, el hacendado prestaba parte de la cosecha del fundo a sus colonos.

"El misti en época de sequía, con escasez de víveres, vendía comida a los colonos. No faltaba de comer. Un colono no tenía plata, pero daba, y cuando ya tenía plata la pagaba. Como crédito era." (Toribio Juli, gr. 2bis.91).

25 El enganche ya fue descrito a finales del siglo pasado por el viajero y espía alemán Kaerger, Karl: Condiciones agrarias de la Sierra Sur Peruana: 1899. Lima, 1979. El hacendado adelantaba un dinero al campesino que luego éste no podía retornar, por lo que debía ceder sus tierras para cubrir la deuda; y sin medios de producción en propiedad, entraba a formar parte de los trabajadores de la hacienda. En los años cincuenta y sesenta, este sistema de reclutamiento de mano de obra aún se mantenía vigente en áreas de selva alta del Alto Huallaga, Cusco, Chanchayo, etc. En realidad se trataba de un sistema de reclutamiento de mano de obra propio de un capitalismo en expansión, pero incapaz de desarrollar un mercado de trabajo libre. Bedoya Garland, Eduardo: Debt Bondage in Peru: The Upper Huallaga Case. Tesis doctoral, University of New York,1994, y "Bonded Labor...".

26 Estos intentos acabaron en fracaso, en buena medida debido a la oposición de los trabajadores colonos. Martínez Alier (Los huacchilleros del...) fue el primero en evidenciarlo. Más recientemente Jacobsen (Mirages of transition...) ha publicado una completa investigación sobre este tema.

27 Deere: Familia y relaciones de clase..., pág. 105. 
Pero a diferencia de lo que otros autores señalan para otras zonas, ${ }^{28}$ las haciendas amantaneñas podían reclamar la devolución de estos préstamos, y a un buen interés:

"En época de escasez los mistis daban comida a los colonos. Después había que devolverlo con creces. Por una arroba de chuño tenían que pagar un quintal de papas." (Manuel Mamani, entr. 8-90).

Es muy posible que en la mayor parte de los casos el hacendado no tuviese la posibilidad de recuperar el préstamo. Pero la existencia de la deuda impedía a los colonos crear capital, pues en ese caso el hacendado podía exigir el pago de la deuda con él contraída. De esta manera, el colono veía limitado su acceso al mercado, porque si acumulaba un capital, ya fuese accediendo al mercado capitalista de trabajo o vendiendo su sobreproducción en el mercado capitalista de bienes, podía ser enajenado por el hacendado en reclamo de la deuda. Ante esta perspectiva, el colono veía más beneficioso mantener la deuda y dedicar su posible sobreproducción a otras actividades, como el sistema de fiestas.

\section{El sistema de fiestas}

Éste participaba en la reproducción de las relaciones de producción existentes entre los campesinos: las generaba y fortalecía. ${ }^{29}$ Pero también ayudaba al sistema de hacienda: extraía los excedentes del colono, impidiendo que pudiese formar un capital con el que acceder al mercado capitalista. ${ }^{30}$

En Amantaní, la mayor parte de las fiestas públicas se mantenían gracias a los cargos de alferado y mayorazgo. El primero costeaba los gastos de tipo religioso (misas, gastos del sacerdote, etc.). El segundo, los propia-

28 Guerrero: La semántica de la dominación....

29 Gose, Peter: Deathy Waters and Hungry Mountains: Agrarian Ritual and Class Formation in an Andean Town. Toronto/Buffalo/London, 1994. Aun siendo de origen colonial, el sistema de fiestas se perpetúa porque acaba formando parte de la lógica económica campesina, y es campesino en cuanto a su ideología y participantes. El campesino ha hecho suya la fiesta aprovechándola como ha podido: los campesinos ricos gastan en su comunidad la riqueza que acumulan al no poderla invertir en el mercado capitalista, y así logran o mantienen estatus (Harris, Marvin: Patterns of Race in the Americas. New York, 1964; Smith, Waldemar R.: El sistema de fiestas y el cambio económico. México, 1981); los pobres fuerzan a los más ricos a asumir cargos festivos para así distribuir esa riqueza e impedir que la acumulación de excedentes en una sola mano pueda conllevar una mayor diferenciación (Mamani, Mauricio: “Agricultura a los 4.000 metros", en X. Albó (comp.): Raíces de América: El mundo Aymara. Madrid, 1988, págs. 75-129).

30 Smith: El sistema de fiestas y...; Brass, Tom: "Cargos and Conflict: the Fiesta System and Capitalist Development in Eastern Peru”, The Journal of Peasants Studies, 13: 3, 1986, págs. 46-62. 
mente festivos (bailes, música, etc). Ambos, además, tenían que preparar chicha y alimentos para toda la comunidad. El extraordinario costo en trabajo y en bienes que suponían las fiestas, y que los patrocinadores debían soportar, era su característica más sobresaliente:

"Yo también hice, hace tiempo, de monamentero (alferado de la Iglesia en las fiestas de Semana Santa). Todos los días de Semana Santa traían los familiares comida, en ollas grandes. El alferado tenía que escavar toda la chacra de papa para que comiese la gente. Cargas de cebada había que moler, para la gente. Y chicha de quinua había que hacer, harto. Y nadie daba plata. Nos teníamos que sacrificar.” (Carmelo Calsín, gr. 2.94).

A cambio de ello recibían prestigio social y político. Los cargos festivos eran ostentados en ocasiones por motu propio; en otras, como resultado de la presión social. Y generalmente, por una combinación de ambos factores. El sistema de fiestas era, pues, coactivo y voluntario a la vez: los más acomodados se veían motivados a aceptar los cargos festivos tanto porque la comunidad esperaba eso de ellos, y en caso contrario podían ser castigados (murmuraciones, pérdida de poder social y político, etc.), como porque sabían que su aceptación les daría prestigio entre la comunidad. El siguiente testimonio de quien ocupara un cargo de autoridad en la Isla deja entrever esta ambivalencia:

"Ese año yo [como autoridad] tuve que llamarlos [a los posibles candidatos]: 'sean amables con los lugareños de Amantaní para nuestra fiesta de Pentecostés y aproximen para recibir [el cargo]'. Tuve que llamarlos. Entonces hay uno que se aproxima voluntariamente. Entonces nombré, y dimos abrazos. Desde ese momento, él se encarga ya.(...) Si no se presenta nadie voluntariamente, las autoridades han de elegir. Pero hay voluntario siempre. Hay unos, hay otros,... Tienen esa fe de recibir, que le dicen Santo Espíritu. Eso pienso. Entonces tienen fe, ellos con toda confianza aproximan: 'yo voy a ser el cargo para año entrante'. Así, de esta forma. Aquellos que no tienen fe, tampoco no aproximan". (Alfredo V. Cari, gr. 1.91).

Por lo común, los cargos festivos eran detentados por miembros de las familias campesinas más solventes; es decir, aquellas que recibían de la hacienda más tierras en usufructo. ${ }^{31}$ Sólo estos grupos domésticos poseían los suficientes medios de producción para acceder a los excedentes que permitían acumular a priori los costos de los festejos, o endeudarse a fin de poderlos sufragar.

31 Las haciendas no otorgaban a todos los colonos la misma cantidad y calidad de terreno en usufructo. De esta manera se impedía la homogeneización del campesinado y se incentivaban las relaciones clientelísticas con el propietario. 
La siguiente transcripción de una entrevista, en la que un ex-colono narra los esfuerzos que tuvo que realizar cuando le tocó el turno de asumir un cargo de alferado, nos descubre como sólo esos campesinos acomodados podían hacer frente a los gastos de las fiestas, y la presión que sobre ellos se ejercía para aceptar los cargos:

"Yo no tenía plata, pero tenía ganados. Ese año era encargado [alferado] de la Iglesia. Sólo la gente de tener era encargado. Había un tal Hilario, que era el que me dijo: entra a la Iglesia. Hilario era el mayordomo. Yo le dije: 'yo no tengo plata, pero tengo ganados, y te daré'. Así exigía. Y me daba velas, incienso,... Rápido pasaban los meses y llegó la Pascua. Yo era alferado de Pascua. Pero cuando llegó Pascua, esa vela, ese incienso, no me llegaba, y tuve que vender más ganado [una vaca]. Luego me dijeron: 'tu vaca ha dado una cría. Bonita, es; ¿por qué has vendido?'. Y yo tenía bastante pena de mi vaca. Así pues, mucha plata gasté.” (Mercedes Calsín, gr. 6.94).

Además, únicamente los colonos más acomodados tenían el suficiente número de allegados con los que sostener parte de la carga del trabajo y de los gastos, allegados que lo eran por ser parientes de sangre o rituales. ${ }^{32}$

A estas fiestas también hay que añadir las que no se mantenían gracias a alferados y mayorazgos, como las de la Candelaria y la de San Sebastián, que se costeaban entre todos los isleños, si bien las autoridades locales eran los que más aportaban. Igualmente los festejos de celebraciones privadas, como el casamiento, suponían un fuerte gasto. La celebración de boda duraba tres días, en los que novios, padres, familiares y padrinos tenían que aportar comida y bebida para todos los invitados.

Por último señalaremos que el hacendado, merced al sistema de fiestas, también podía salir beneficiado en otros dos aspectos. Por un lado, era habitual que la situación de dependencia del colono con cargo festivo aumentara, pues normalmente se veía obligado a endeudarse con su patrón para poder hacer frente a los gastos ceremoniales:

"Los patrones ayudaban a los alferados, para su plata. Entonces los colonos, de todo dependían de sus patrones." (Pedro Juli, gr. 5.94).

Por otro, en muchas ocasiones la mayor parte de los excedentes colonos destinados a gastos ceremoniales acababan en manos del hacendado en forma de ganancia comercial, al proveer a los campesinos de los productos necesarios para las celebraciones (alcohol, coca, velas, etc.).

32 Los colonos mejor situados económicamente, que solían ser mayordomos y quipus de las haciendas, eran los individuos más solicitados por parte de los demás amantaneños como compadres y padrinos, pues su posición en la hacienda les permitía conceder favores a sus allegados. 


\section{El papel de terceros agentes}

No eran los hacendados los únicos actores sociales que extraían la sobreproducción y el sobretrabajo colono. Otras figuras, como la del sacerdote, utilizaban su cargo para obtener prerrogativas económicas:

"Los casamientos sólo se hacían el tres de mayo, y había que pagar al sacerdote gallinas. Si no, no casaba. También había que darles lo mejor de la cosecha." (Manuel Mamani, entr. 8-90).

Bodas, entierros, festividades... Hacía retribuir su participación en todos los eventos en los que el campesino se veía forzado a solicitar su asistencia.

Pero quienes han quedado en la memoria de los amantaneños como los individuos más abusivos son las autoridades políticas del distrito de Capachica, a cuya jurisdicción perteneció Amantaní hasta la década de 1960. ${ }^{33}$ Estos personajes eran temidos por los campesinos, pues todo contacto con ellos siempre conllevaba su explotación como mano de obra gratuita o la pérdida de bienes materiales: tenían que realizar servicios personales para el gobernador y de arreglo de infraestructuras en el pueblo de Capachica:

"Antes era difícil vivir (...). En ese tiempo también teníamos que ir a Capachica. Y con la hacienda, dos servicios teníamos. Si entonces había hacienda, ¿por qué también teníamos que ir a Capachica a trabajar?. ¿Por qué dos servicios?. Eso no me explico." (Mercedes Calsín, 6.94).

Las autoridades isleñas debían desplazarse todos los domingos para recibir órdenes de las autoridades distritales, lo que éstas aprovechaban para imponerles multas si no podían asistir:

"El gobernador de Capachica, para las Fiestas Patrias hacía trabajar. Arreglar el suelo. Así, esas cosas. Las autoridades tenían que estar presentes en Capachica cada domingo. Si no les hacían pagar multa, se hacían pagar su trago. A la fuerza había que llegar, aun con lluvias, con viento." (Manuel Mamani, gr. 7.91).

33 Calisto, Marcela: Peasant Resistence in the Aymara Districts of the Highlands of Peru, 1900-1930: An Attempt at Self-Governance. Tesis doctoral, University of California. 1993; afirma que uno de los factores causales esenciales que permiten explicar las rebeliones puneñas es la frustración del campesino ante el papel mediador ejercido por las autoridades políticas locales. Estos mostraban al Estado, institución con la cual los campesinos no podían relacionarse directamente, un dibujo distorsionado de la realidad en favor de los intereses gamonales. 


\section{Los cargos festivos también tenían que trasladarse a Capachica para realizar onerosos gastos ceremoniales:}

"A hacer fiesta íbamos a Capachica. Mucho gasto era, pues todo de comida había que llevar: quispiño, chicha de quinua,... Harto de todo. Los familiares también tenían que ir, con su olla de comida." (Carmelo Calsín, gr. 2.94).

Además, cuando visitaban Amantaní, robaban ropas y alimentos a los campesinos; $;^{34}$ etc.

"Luciano Supo siempre era teniente-gobernador. Nunca dejaba de serlo. De Capachica era. Siempre venía a la Isla. Venía como comisión, de orden del gobernador, para notificar cosas a los de Amantaní. Luciano a la gente no trataba bien. Se apropiaba de su ropa. (...) El gobernador se aprovechaba. El no venía directo. Mandaba a los teniente-gobernadores, y se llevaban ropa, palo,... Siempre cargaban." (Simón Calsín, gr. 1.92/93).

La presión de las autoridades distritales era tan fuerte que, en varias ocasiones, los isleños se dirigieron a instancias políticas más elevadas en demanda de justicia. ${ }^{35}$

En resumen, mediante multas, cobros abusivos y enajenaciones violentas, las autoridades distritales y el bajo clero se apropiaban de parte de la sobreproducción campesina, y mediante trabajos gratuitos, personales y para la colectividad, de parte de su sobretrabajo. ${ }^{36}$

34 Ávalos de Matos, Rosalía: "L'organisation sociale dans l'ille Taquile", Travaux de l'Institut Francais d'Etudes Andines, 3, 1951, págs. 74-87, que realizó trabajo de campo en los primeros años de la década los cincuenta en la isla de Taquile, vecina a Amantaní, recuerda como... “...hasta una época reciente, las autoridades de Capachica llegaban a menudo de noche y hacían por sorpresa una verdadera razzia de productos de la Isla”. [la traducción es nuestra]

35 En una carta fechada el 5 de abril de 1918, el amantaneño Lorenzo Pacompía se quejaba al subprefecto del Cercado de Puno de que el gobernador de Capachica le había maltratado por negarse a viajar a Bolivia para comprarle productos (Calisto, Marcela: "Campesinos puneños y resistencia cotidiana, 1900-1930", Allpanchis, 37, 1991, págs. 169-202). Igualmente, en otro oficio con fecha del 12 de enero del mismo año y dirigido a la Prefectura de Puno, Lucas Ramos y Mariano Mamani protestaban por los abusos del gobernador. El documento, encontrado en posesión del amantaneño Ambrosio Mamani, finaliza así: "A Ud. ocurrimos, suplicándole se sirva disponer de una manera terminante que el Gobernador de Capachica, nos deje en plena libertad para atender a nuestros sembríos i demas labores agrícolas, lo mismo que a nuestros compañeros Sebastián Pacompía, Gerónimo Mamani, i en general para todos los indígenas de la mensionada isla de Amantaní; teniendo presente que nosotros no molestamos a nadie, ni pretendemos nada de lo ajeno, exijiendo únicamente se nos conceda libertad, no se nos persiga, ni se nos obligue a prestár servicios que ya fueron suprimidos, como es el pongeaje; amparándosenos en la posesión de los terrenos, en que hoy nos hallamos."

36 Este estado de cosas no era particular de Amantaní. Por el contrario, eran prácticas bastantes generalizadas en la región. Urquiaga, José: Indios: Puno-1916. Lima, 1977, un terrateniente de la provincia de Azángaro comprometido en las luchas internas gamonales del departamento de Puno a principios de siglo (Burga y Flores Galindo: Apogeo y crisis de...), se quejaba en 1916 de las extralimitaciones de curas, gobernadores y jueces con los campesinos: recibían servicio de punku y mitamae, 
Los propietarios de las haciendas no se oponían a esta explotación de sus colonos por terceras personas; por el contrario, lo aceptaban de buen grado. Autoridades, religiosos y hacendados vivían en una relación simbiótica: a cambio de la utilización de la mano de obra controlada por los fundos y de la obtención de parte de sus excedentes, el cura adoctrinaba a los colonos en favor del hacendado, y las autoridades vetaban las protestas que realizaban por medios legales. Y sobretodo, ayudaban a mantenerlos aislados del mercado capitalista al extraerles parte de sus excedentes.

En otras palabras, autoridades y sacerdotes recibían parte del excedente extraído a los colonos en su papel de "clases subsumidas"; es decir, porque proporcionaban ciertos procesos de tipo económico, cultural y político que aseguraban la existencia y la reproducción de la "clase fundamental" hacendada y de la relación social de producción servil.

\section{Conclusiones}

La coerción sorda de las relaciones económicas no explica por sí sola el mantenimiento del sistema de hacienda. Ésta también generó y utilizó estrategias extraeconómicas de control de la mano de obra campesina.

Una de ellas es la incentivación de la diferenciación campesina, que se lograba mediante el establecimiento de una jerarquía dentro del fundo, o concediendo en usufructo lotes de terrenos de tamaño y calidad diferentes. Tal estratificación no se basaba en estamentos infranqueables; por el contrario, el sistema promovía la movilidad social, al dar a los colonos expectativas de promoción. Esto suscitaba la competencia y la búsqueda de pactos de tipo clientelístico con el propietario, que era quien permitía esa promoción, ya fuese donando más tierras en usufructo o cambiando los cargos de la hacienda.

Otras estrategias iban dirigidas a incrementar el aislamiento físico en el que el amantaneño vivía: no desarrollo de los medios de comunicación; ${ }^{37}$

\footnotetext{
obligaban a las autoridades indígenas a prestarles servicios personales gratuitos, etc. Estas afirmaciones parecen coincidir con la realidad, aun cuando las declaraciones de Urquiaga han de ser tomadas con precaución, pues la defensa del indígena era frecuentemente utilizada en el discurso de los diferentes sectores gamonales enfrentados entre sí para esconder una lucha por la tierra y por el control de la mano de obra campesina (García Jordán, Pilar: Iglesia y Poder en el Perú Contemporáneo: 1821-1919. Cusco, 1992).

37 Hasta mediados del siglo XX no se construyeron las primeras barcas de madera, más rápidas, seguras y con mayor capacidad de carga que las tradicionales balsas de totora.
} 
impedimentos a la educación formal del campesino; prohibición de que realizase el servicio militar, etc. Finalmente, tampoco fue extraño en Amantaní la utilización de mecanismos estrictamente represivos, como el uso de la violencia física o el control de los aparatos de justicia. ${ }^{38}$

Sin embargo, pensamos que la coerción económica es la fundamental a la hora de explicar la dominación socio-política y la explotación económica que el sistema de hacienda mantenía sobre la población colona. Y es que era esencialmente cuando este tipo de coerción entraba en crisis, cuando el amantaneño establecía movimientos de resistencia; es decir, cuando los mecanismos de control se colapsaban.

No fueron extraños los procesos de resistencia entre los amantaneños, al menos desde el último tercio del siglo XIX, cuando su acceso a los medios de producción y el aislamiento económico entraron en crisis. El sistema de hacienda necesitaba un determinado nivel de población; era un sistema formado cuando la mano de obra era un bien escaso, y por ello se basaba en unas relaciones de producción que ataban a los trabajadores e incentivaban su reproducción. Pero en la segunda mitad del siglo XIX, el número de colonos empezó a superar el nivel óptimo que exigía el buen funcionamiento del sistema; ahora el bien escaso no era la fuerza de trabajo, sino la tierra. ${ }^{39}$ En estas circunstancias, el sistema podía reaccionar de cuatro maneras: desarrollando los medios de producción e intensificando la agricultura; mediante una expansión territorial; cediendo mayor cantidad de tierra en usufructo a la población colona y reduciendo la sobrepoblación relativa; expulsando a la mano de obra excedente.

La primera posibilidad ni se planteó, como sucedió en toda la región surandina peruana ${ }^{40}$ La segunda no fue posible por razones obvias, ya que Amantaní es una isla. Sólo quedaban dos posibilidades: una que favorecía a los campesinos, pero que suponía la reducción de las ganancias de la hacienda, y otra que beneficiaba a los propietarios, pero que conllevaba la

38 Gascón Gutiérrez, Jorge: Mecanismos de dominación y resistencia campesina en la hacienda surandina peruana (Isla de Amantaní-Lago Titicaca). Tesis de licenciatura, Universidad de Barcelona. 1997; en ella hemos hecho un estudio más profundo y exhaustivo de estos mecanismos de control extraeconómicos.

39 Mörner, Magnus: En torno a las haciendas de la región del Cusco desde el siglo XVII. Cusco, 1977.

40 Alrededor de la imposibilidad de las haciendas surandinas peruanas de intensificar su producción se ha generado un intenso debate, que hemos explicado en Gascón Gutiérrez, Jorge: "Recreando la propia historia: Luchas campesinas e historia oral en una comunidad del altiplano peruano (Isla Amantaní, Lago Titicaca)", en García Jordán/Izard/Laviña (coord.): Memoria, creación e historia: Luchar contra el olvido. Barcelona, 1994, págs. 305-318; y Mecanismos de dominación y... 
expulsión de parte de los campesinos. Ninguna de las dos fue posible. La primera, porque los hacendados no tenían la intención de disminuir sus rentas. La segunda, porque la expulsión de los colonos de la hacienda habría supuesto el colapso de los factores coercionadores sordos de las relaciones económicas: si el acceso a los medios de producción no estaba asegurado, el buen funcionamiento de los mecanismos de dominación tampoco lo podía estar.

Ante el crecimiento demográfico, el hacendado intentó reducir los beneficios de sus colonos, aunque sin expulsarlos. Esto se concretó en una mayor dificultad para las generaciones más jóvenes en el establecimiento de nuevos contratos de colonato, y en una menor cantidad de tierras en usufructo en estos nuevos contratos. Pero el sistema no se planteó establecer algunas nuevas ventajas para el amantaneño en contraprestación, tal como una disminución en la enajenación del excedente campesino, que le habría permitido acceder a los mercados de bienes y de trabajo temporal y mantener un nivel de vida semejante al de las generaciones precedentes; esto habría acabado con el segundo nivel de la coerción sorda de las relaciones económicas. De esta manera, los factores coercionadores sordos se relajaron (si no había los suficientes medios de producción, no se podía esperar que los mecanismos de control funcionasen), y se produjeron violentos levantamientos campesinos. Finalmente, las haciendas tuvieron que ceder y permitir a sus trabajadores la relación directa con el mercado capitalista; en otras palabras, el segundo nivel de la coerción sorda se vino abajo.

A partir de ahí, el sistema entró en una crisis irreversible. Fue un proceso largo, que duró siete u ocho décadas, pero que supuso el fin de las haciendas en Amantaní tras más de cuatro siglos de existencia. 